\title{
New measures for access to emergency food
}

\author{
Food banks, food pantries and other emergency food operations are often overlooked in studies of food access. \\ Their availability for patrons should not be expressed in terms of geographic coverage, but rather their capacity and \\ hours of operation.
}

\section{Jerry Shannon}

E mergency food operations have developed dramatically in the United States since the 1980s, in part due to cut backs to social assistance programmes such as Temporary Assistance to Needy Families or the Supplemental Nutrition Assistance Program ${ }^{1}$. At the national level, Feeding America has emerged as a leading actor, managing a complex system of food distribution through a network of regional food banks. These food banks, in turn, work with food pantries at local organizations to directly distribute food to individuals facing food insecurity. Feeding America reports providing food assistance to 46.5 million individuals nationally, though the United States Department of Agriculture estimates the number of individuals using food pantries to be a more modest 17.6 million individuals ${ }^{1}$. Writing in Nature Food, Daniel Knudsen and colleagues advance research in food accessibility by analysing this key, but understudied, aspect of the food environment ${ }^{2}$. Focusing specifically on emergency food sources in south-central Indiana, they create new metrics that evaluate the temporal availability of pantries as a food source.

Most existing research on food accessibility has focused on retail outlets rather than on emergency food operations, and several key aspects of this work remain unsettled. Empirically, geographic proximity to supermarkets and other retailers offering a broad selection of healthy foods (for example, produce and meats) has had limited association with health outcomes such as dietary-related chronic conditions and obesity ${ }^{3}$. Most research has focused on food purchased for at-home consumption, despite evidence that access to fast food ${ }^{4}$ or other non-retail sites may also play significant roles ${ }^{5}$. Furthermore, work on food access has often neglected individuals' everyday food procurement habits ${ }^{6}$ and the temporally variable nature of food access, including factors such as store operating hours 7 . At a broader level, a focus on mapping and labelling areas with poor food access may both stigmatize already marginalized communities and distract from more systemic issues such as retailer consolidation and neighbourhood disinvestment ${ }^{8}$. Notably understudied in food access research are emergency food sites - which Knudsen and colleagues address, as well as several of the problematic elements identified here. While some authors have argued that emergency food organizations have given more attention to meeting food needs than addressing the factors that create them ${ }^{9}$, food pantries do provide immediate assistance to many food-insecure households.

Few spatial analyses of food access have included emergency food sites. This is in part due to the uniquely difficult challenges in working with these data. Unlike retail food outlets or restaurants, there are no widely available sources of data on these agencies, meaning that researchers must contact individual food banks directly for information. Furthermore, these data can require extensive ground-truthing. Some agencies may not be public facing, such as domestic violence or homeless shelters. Local food pantries have widely varying schedules, and some listed agencies may be currently inactive. Food pantries may also vary greatly in size. As a result, researchers such as Knudsen and his collaborators have to personally contact each agency in their study area to confirm their status.

Knudsen and colleagues' work stands out for its explicit attention to temporal limitations in food access. A growing body of research has incorporated store operating hours for food retailers ${ }^{10}$, but this approach is more difficult for food pantries, whose operating hours may vary widely. Therefore, Knudsen and colleagues develop two measures of accessibility with explicitly temporal components. For each emergency food organization, the pantry accessibility index (PAI) is a ratio that incorporates pantry availability measured through operating hours, use restrictions and travel time - and an estimate of need based on existing food insecurity estimates. At the census-tract level, the individual accessibility index (IAI) provides a similar metric for measuring available emergency food sources. More simply put, PAI is a measure of how geographically accessible a pantry is given the needs of its surrounding population and IAI rates the availability of food assistance at the census-tract level based on local emergency food options.

Knudsen and colleagues' work describes these measures and provides a case study of their use in south-central Indiana. Academically, many initial studies of temporally variable access to food sources have drawn on the spacetime prism approach pioneered by Hägerstrand ${ }^{10}$. Knudsen and colleagues' approach provides an alternative measure analogous to existing approaches in healthcare access ${ }^{11}$. It also has relevance for regional food banks, who are often actively engaged in working with local organizations such as houses of worship to develop new food options in underserved communities. Both PAI and IAI are complicated measures requiring statistical interpretation, and so more can still be done to make these useful for local administrators.

The key contribution of the authors' research is providing reproducible methods that highlight geographic disparities in access to emergency food organizations. Future work might consider drivers of identified disparities, which may include factors such as a lack of local volunteer capacity and organizational resources. These may in turn be the result of ongoing economic and social marginalization. This research also does not include daily mobility patterns for households, which may certainly affect levels of access. Still, Knudsen and colleagues' work does develop tools that make differences in geographic access to emergency food systems more legible.

At the time of this review, many face massive economic uncertainty due to the economic consequences of the COVID-19 
outbreak. Through careful attention to the landscape of resources available to affected households, including the emergency food system, research building on Knudsen and colleagues' work may help bolster local preparedness and resilience.

Jerry Shannon $\bowtie$

Department of Geography and Department of Financial Planning, Housing and Consumer

Economics, University of Georgia, Athens, GA, USA. $凶_{e-m a i l: j s h a n n o n @ u g a . e d u}$

Published online: 19 May 2020

https://doi.org/10.1038/s43016-020-0081-2

References

1. Heflin, C. \& Price, A. J. Hunger Environ. Nutr. 14, 225-239 (2019).

2. Kaplan, K. H. et al. Nat. Food https://doi.org/10.1038/s43016-0200079-9 (2020).

3. Caspi, C. E., Kawachi, I., Subramanian, S. V., Adamkiewicz, G. \& Sorensen, G. Soc. Sci. Med. 75, 1254-1262 (2012).

4. Cooksey-Stowers, K., Schwartz, M. B. \& Brownell, K. D. Int. J. Environ. Res. Public Health 14, 1366 (2017).
5. Shannon, J. Ann. Am. Assoc. Geogr. 106, 186-202 (2016).

6. Colón-Ramos, U. et al. Public Health Nutr. 20, 1941-1952 (2017).

7. Widener, M. J. \& Shannon, J. Health Place 30, 1-3 (2014).

8. Reese, A. M. Black Food Geographies: Race, Self-reliance, and Food Access in Washington, D.C. (UNC Press, 2019).

9. Poppendieck, J. Sweet Charity? Emergency Food and the End of Entitlement (Viking, 1998)

10. Chen, X. \& Clark, J. Profess. Geogr. 68, 175-188 (2015).

11. Bissonnette, L., Wilson, K., Bell, S. \& Shah, T. I. Health Place 18, 841-853 (2012).

Competing interests

The author declares no competing interests. 